\title{
Parametric Fault Detection of Analogue Circuits
}

\author{
Sherif Anas \\ Egyptian Armed \\ Forces
}

\author{
Mohamed H. El- \\ Mahlawy \\ Egyptian Armed \\ Forces
}

\author{
Mahmoud E. A. \\ Gadallah \\ Modern Academy, \\ Maadi, Cairo, Egypt
}

\author{
Emad A. El- \\ Samahy \\ Egyptian Armed \\ Forces
}

\begin{abstract}
This paper presents a new testing approach for analogue circuits based on the digital signature analysis. In this paper, the efficient parametric fault detection approach for analogue circuits using the simulation environment is presented. This approach has three main parts, an analogue test pattern generator (ATPG), an analogue test response compactor (ATRC), and an analogue circuit under test (ACUT) model, build in the PSpice circuit simulator. The proper ATPG is designed to sweep the applying sinusoidal frequencies to match the frequency domain of the ACUT. The output test response of the ACUT is acquired via the analogue-to-digital converter (ADC). The ATRC accumulates digital samples of the output response from the ADC to generate a digital signature that can characterize the situation of the ACUT. The signature comparison is achieved based on signature boundaries based on the worst-case analysis. In addition, the signature curve for each component variations of the ACUT is presented to be illustrated as image of some parameters affected in the transfer function of the ACUT. It combines effective parameters of the transfer function of the ACUT with respect to the component variations. These parameters are the band-with and the passband transmission. Using the signature curve, a parametric fault of each component of the ACUT can be detected under the sweep sinusoidal frequency of the ATPG. The presented testing approach is applied to the analogue benchmark circuit to validate the presented testing approach.
\end{abstract}

\section{General Terms}

Modeling of analogue circuit testing.

\section{Keywords}

Fault detection, Parametric faults, Signature analysis of analogue testing, Testing of analogue circuits.

\section{INTRODUCTION}

Automatic testing techniques play a great role in industrial applications. They are considered as standard way for detecting faults in analogue electronic systems. Researchers are concentrated their major attention to the automatic testing of the digital systems [1-7]. However, in most cases the digital system exists within an analogue enclosure system. This analogue part of the mixed-signal system requires to be tested for increasing the system performance. Testing applications of analogue circuits are still in research phase. In general, the most challenge of fault detection of the analogue circuits is to unify test procedures to properly generate test signals that are capable of stimulating faults, and to compact the test response for fault detection [8]. The analogue testing has to fit the specifications of the ACUT [9]. In addition, the modeling of hardware defects of the ACUT and the usage of these models for developing and improving test signals is considered another analogue testing challenge.

The manufacturing defects may have two types of permanent faults, namely catastrophic (hard) or parametric (soft) faults
[10]. A catastrophic fault is one in which discrete component of a circuit is destroyed (e.g. short circuit, open circuit as well as topological change). With parametric fault, the component is still functioning but out of nominal tolerance band (out of specification). Figure 1 depicts the classification of analogue circuit faults. The range of the acceptance for the good ACUT, and the non-acceptance are illustrated for $\pm 5 \%$. Comprehensive researches have been conducted on analogue testing issues. Faults in an analogue circuit may occur due to a catastrophic fault model, considered easily to test. In the parametric fault model, it is hard to test, and its effect is represented by means of the change in circuit output signals.

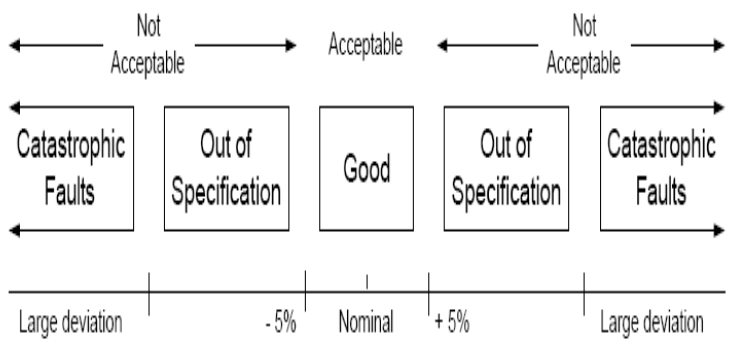

Fig 1: Classification of analogue circuit faults.

Several testing techniques for analogue circuits are attempted. Some testing approaches aim to test analogue circuits based on approximated impulse and step test signals [11-17]. The limitation of these approaches is the requirements generation of the ideal impulse. Therefore, an approximation of largeamplitude and narrow-duration is performed. As an impulse signal is shortened, its amplitude must be increased, and this may overload the ACUT. The shape and scale of the frequency spectrum of an impulse response or a step response is fixed. In other word, the power cannot be concentrated to any arbitrary frequency bands, which is not useful to target specific faults. In addition, impulse and step responses can characterize only linear system, which limits their applicability. The other testing approaches aim to test analogue circuits based on the input binary sequence [18-20]. They require extra hardware for stimulus generation and extra hardware at the output for analogue test response analysis (e.g. ADC or cross-correlators). Binary sequence (Square wave) has fixed frequency spectrum shape depending on the clock frequency. Its frequency spectrum follows the shape of the $(\sin (x) / x)$ function and includes only the odd harmonics. The binary signals (Impulse, step, square wave and binary sequence) cannot have more power at any arbitrary frequency bands. Thus, they cannot effectively excite the ACUT at prespecified parts of the frequency spectrum.

Another testing approach aims to test analogue components in mixed-signal circuits, based on oscillation-based BIST (OBIST) methodology [21]. The limitations with that approach are that the catastrophic faults are considered only. The Multi-Detect test method for test generation is another test approach to identify a set of sinusoids. It forms the test 
set that maximizes the difference between the responses of the good and faulty ACUT [22]. A faulty circuit is detected from a deviation of its oscillation parameters. The detection circuitry is provided by a single reference value as a reference input to the response comparator instead of multiple reference values for all faults in an ACUT. The limitations of that approach are the problem of finding the minimum detectability threshold between good and faulty circuits for detecting a fault. Estimating the detectability threshold for a given fault is affected by increased number of components, tolerances associated with each component, evaluation of the complex equations, and measurement accuracy of the response analysis circuit (i.e., comparator circuit). Therefore, this approach became too expensive in terms of computation time. Any attempt to reduce the computation time by using simple design models may result in inaccurate detectability threshold value. The testing approaches, based on wavelet filters to analyze and compress signatures [23], depend on acquiring the ACUT output response, and processing this response via an array of filters, each operates within a defined band, followed by a signature generator and comparison module for each band. The limitation of that approach is not using the multi-tone test input. Since a single frequency component is not effective in detecting faults.

From the most collected published testing approaches of analogue circuits, the practical implementation of the analogue testing focused on the detection of the catastrophic faults in the ACUT, but it has a shortage of the testing application of parametric faults in the ACUT. The main motivate is to build an efficient analogue testing scheme including the multi-test pattern generation capabilities (ATPG) to match the ACUT, the ATRC to characterize the ACUT based on inserted faults and component tolerances. The main objective of this paper is to design, analyze, evaluate, and verify the parametric fault detection approach for analogue circuits using a simulation environment. The proper ATPG is designed to sweep the applying sinusoidal frequencies to match the frequency domain of the ACUT and then is acquiring the output test response, via the ADC. The analogue test response compactor (ATRC) acquires and then compacts digital samples of the output response to generate a digital signature that characterize the situation of the ACUT. The signature comparison is achieved based on the precalculated signature boundaries, calculated based on the worst-case analysis of both the minimum and the maximum of the output analogue response of the ACUT using PSpice circuit simulator. In this paper, the presented testing approach enables to achieve the concept of the signature curve generation for each component of the ACUT. Based on this curve, the relation between the digital signatures and the component variations of the ACUT is presented. The signature curve combines the effects of both the band-with (BW) and the passband transmission (Amax) in the amplitude response of the ACUT with respect to the component variations of the ACUT.

This chapter starts with the introduction summary of the new analogue testing approaches. The second section is concerned with the design of the presented new analogue testing approach. Then, the next sections will focus on the PSpice circuit model simulation of the ACUT and the parametric fault analysis of the selected ACUT as case study. Finally, conclusions and contributions obtained in this paper.

\section{DESIGN OF THE NEW ANALOGUE TESTING APPROACH}

The objective of the presented analogue testing approach is to design the proper ATPG (stimulus) for stimulating the highest possible proportion of all faults, and to design the proper ATRC that can detect the stimulated faults. The main block diagram of the analogue testing architecture, presented in this paper, is shown in Figure 2. This testing architecture is suitable in the external testing approach. The ATRC consists of three sub-modules; the rectifier, the ADC, and the test response compactor (TRC). The rectifier is designed to rectify the negative analogue signal to positive one in the case of the bipolar signals. The ADC is used to convert the analogue signal of the output response of the ACUT into the digital samples. The TRC, composed of the double-precision accumulator, accumulates and compacts the generated samples to produce a digital signature.

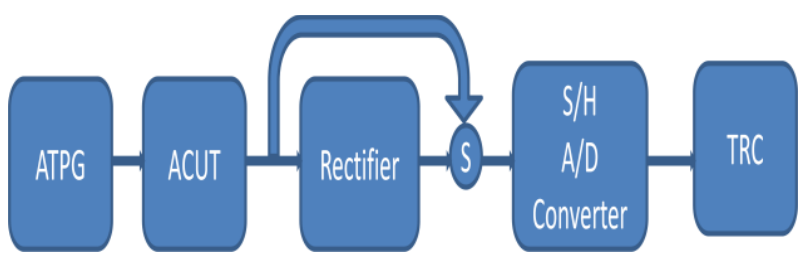

Fig 2: Main block diagram of the presented analogue testing approach.

Most of faults in analogue circuits can affect the frequency response of the ACUT. Therefore, in this architecture, the proper ATPG is designed to sweep the applying sinusoidal frequencies that provide a stimulation to detect faults in a wide range of analogue circuits. The frequency sweep in the sinusoidal waveform can exercise the frequency response of the ACUT. The existence of faults can affect the frequency response of the ACUT, and change the output waveform of the ACUT. Therefore, the change of the generated digital signature from the ATRC will be significant. The transfer function coefficient variations of the ACUT will prevent an exact output response sequence. Unique digital signature cannot be obtained for the fault-free ACUT. Therefore, in this paper, the ATRC function is an accumulator that sums the sample magnitude of the absolute analogue output response. This facilitates the determination of a range of good digital signatures to account for acceptable changes in the output response due to component variations of the transfer function coefficient of the ACUT. The analogue output response is generated from the circuit model of the ACUT to verify the effectiveness of this presented analogue testing approach.

During analogue fault simulation, many parametric faults have been considered for each component of the ACUT, including $\pm 5 \%, \pm 10 \%, \pm 20 \%, \pm 50 \%, \ldots$ variations of specified component values, short-circuit and open-circuit (i.e., very small value and very large value) in the component of the ACUT. The analogue fault simulation of the ACUT is performed using in the PSpice circuit simulator to illustrate the effectiveness of the new digital signature approach for analogue fault detection technique. Digital signatures based on the accumulation absolute sum of the sample magnitude of the ACUT outputs during test window can be plotted against the selected component variations of the ACUT, called signature curve with respect to that component. This curve illustrates the classification of the fault-free and the faulty ACUT with respect to that component based on parametric faults. 


\subsection{Analogue test pattern generator}

The frequency change of the input signal, applied to the ACUT, controls the amplitude response of the output response. The rate of the frequency sweep is not a constant, but it may vary with each new generated cycle of the ATPG. In this section, the sweep sinusoidal frequency extraction procedure is used to affect the amplitude response of the ACUT and consequently affect the output response of the ACUT through its time domain $\mathrm{I} / \mathrm{O}$ relation. Figure 3 illustrates the simulation model of the ATPG in this analogue testing architecture [24]. It is the modeling of voltage controlled oscillators (VCOs) using PSpice circuit simulator. It consists of two parts; the Sin Source Model, and the Integrator Model. A simple form of the VCO is obtained by starting with the time domain function for a sinusoidal source model $(\sin ((2 \pi \times f c \times$ time $)+$ phi $))$. In this example, $2 \pi$, fc and phi are all constant global parameters. The single frequency source can be turned into a VCO by making phi a function of a controlling voltage instead of a constant. $y(t)=$ $\sin (2 \pi \mathrm{fct}+\varphi(t))$. The instantaneous frequency is given by the time derivative of total phase: $2 \pi \mathrm{finst}=2 \pi \mathrm{fc}+\varphi^{\prime}(\mathrm{t})$. The relationship between the frequency deviation $\mathrm{fd}=$ finst $-\mathrm{fc}$, and $\square \varphi \square \square$ is given by: $\varphi(\mathrm{t})=\int 2 \pi \mathrm{fd}(\mathrm{t}) \mathrm{dt}$. For a linear VCO, we want fd to be proportional to the controlling voltage vetrl, therefore: $\varphi(t)=2 \pi \mathrm{k} 1 \int_{\mathrm{vctrl}}(\mathrm{t}) \mathrm{dt}$, where $\mathrm{k} 1$ is in Hertz/volt. Using PSpice circuit simulator [24], the integrator can be modeled as a controlled current source plus a capacitor. The varying phase term is added into the controlled voltage (Sine) source.

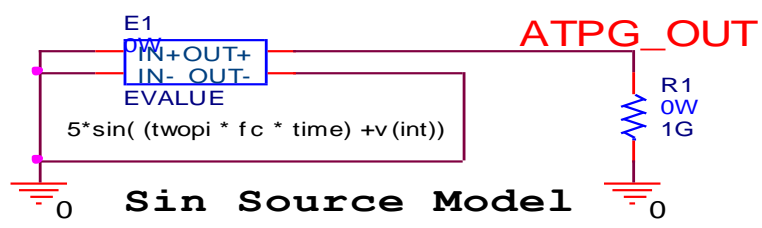

PARAMETERS:

twopi $=6.283$

k1 $=32.5 k \quad$ Integrator Model

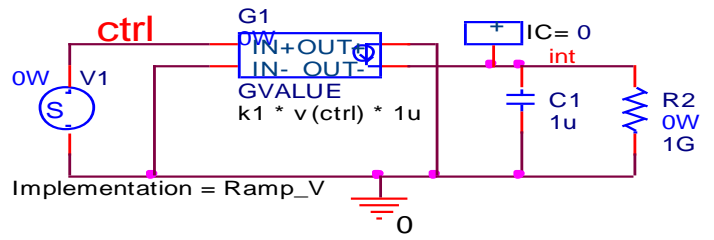

Fig 3: Model of the ATPG model in the PSpice simulation.

Figure 4 shows the timing diagram of the two main control input signals for the VCO model. Control signal CTRL controls the frequency sweep to produce the output signal ATPG_OUT. The generated signal is the mix of multifrequency sinusoidal signals. Figure 5 illustrates the Fast Fourier Transform (FFT) of the output signals of the ATPG model from $100 \mathrm{~Hz}$ to $10 \mathrm{kHz}$. The amplitude is set to $5 \mathrm{Vpp}$, fc is set to $100 \mathrm{~Hz}$ and $\mathrm{k} 1$ is set to $32.5 \mathrm{kHz} /$ volt, according to the model in Figure 3. In addition, Figure 6 shows the FFT of the output signal of the ATPG model. The amplitude is set to $5 \mathrm{Vpp}, \mathrm{fc}$ is set to $1.2 \mathrm{~Hz}$ and $\mathrm{k} 1$ is set to $3.8 \mathrm{kHz} / \mathrm{volt}$. The extracted sinusoidal signals have the frequency sweep from $1.2 \mathrm{~Hz}$ to $1.5 \mathrm{kHz}$. All curves in Figure 5 and Figure 6 can be used to stimulate analogue filter circuits in the frequency range of the biomedical applications.

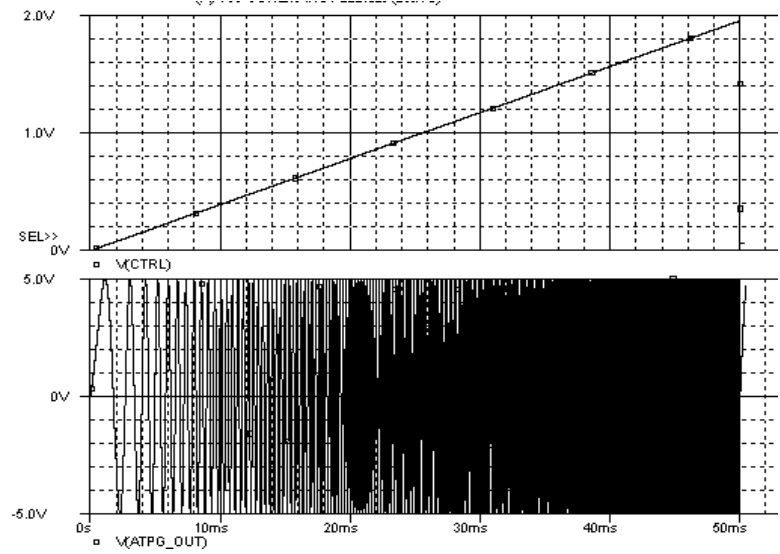

Fig 4: Timing diagram of the ATPG model using the PSpice simulation.

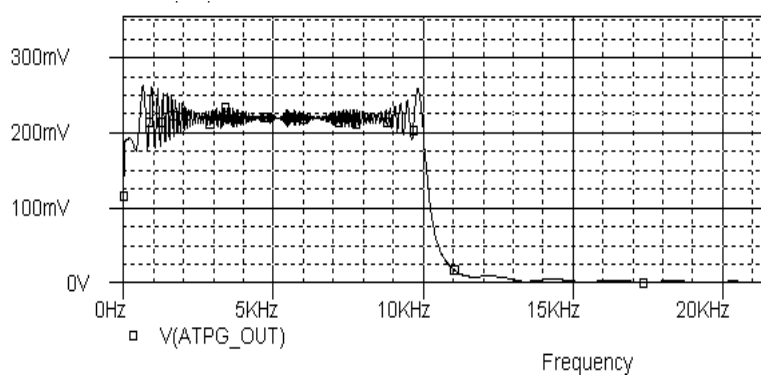

Fig 5: FFT of the output signals of the ATPG model.

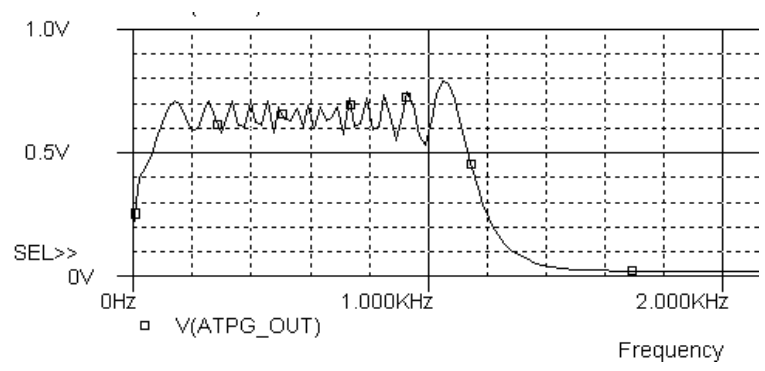

Fig 6: FFT of the output signal frequency from $1.2 \mathrm{~Hz}$ to $1.5 \mathrm{kHz}$.

\subsection{Full rectifier circuit and Analogue-to- digital converter}

According to Figure 2, the output signal of the ATPG model is applied to the ACUT whose output signal is applied to either the full rectifier circuit or the ADC. The output waveform of the rectifier stage produces unified signal waveform in the positive polarities. The schematic diagram of the full rectifier circuit is shown in Figure 7 [17]. The output signal of the traditional bridge full rectifier has different ground reference. But, the unified signal of the presented rectifier circuit has the same reference ground of the input signals. It is represented by two operational amplifiers (U5B, U5B) in the same integrated circuit (LM324), resistors R4, R5, and R6 and diodes D1, D2, D3, and D4. During the positive direction of the input Sine waveform, diodes D1 and D4 are off and D2 and D3 are on. During the negative direction of the input Sine waveform, diodes D2 and D3 are off and D1 and D4 are on. The unified signal, generated from the rectifier, is applied to an 8-bit ADC model in the PSpice circuit simulator. 


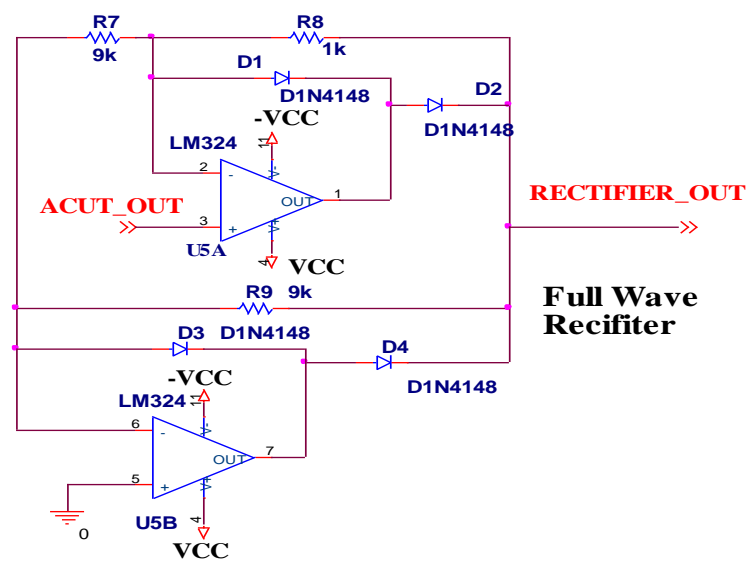

Fig 7: Schematic diagram of the full rectifier circuit.

The ADC is the main part of data acquisition systems. To process applied signals, the sample and hold $(\mathrm{S} / \mathrm{H})$ process and data conversion are required. Figure 9 shows the schematic diagram of 8-bit ADC model. The control signal $\mathrm{S} / \mathrm{H}$ is generated to place the input analogue signal ADC_In in the sample mode and the hold mode, and the control signal RESET is generated to start of the data conversion cycle. The proper data conversion is to sample the analogue signal in the sample mode, and holds the signal constant during the hold mode. The timing is adjusted so that the encoder performs the conversion during the hold time. The control signal $\mathrm{S} / \mathrm{H}$ clocks the ADC and the input analogue signal ADC_In is converted. Once a conversion cycle is started, it cannot be stopped or restarted until the data conversion cycle is complete and the data is available from the binary output, $A[8: 1]$. Figure 8 illustrates the external connections for the ADC in unipolar input mode. The first output code transition from 00000000 to the full-scale transition 11111111 . The binary data output of the ADC is applied to the test response compactor (TRC) Stage.

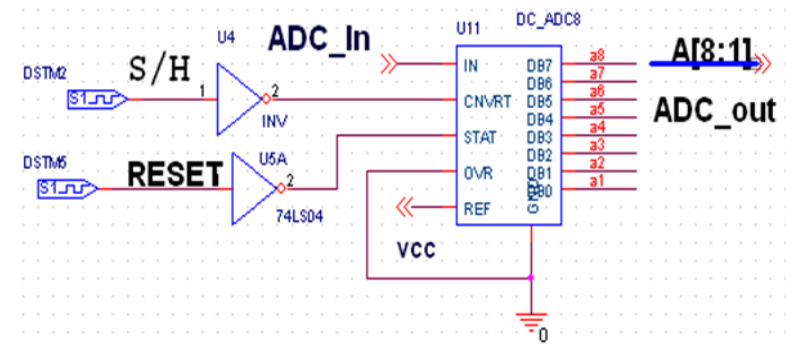

Fig 8: Schematic diagram of the 8-bit ADC model in PSpice simulator.

\subsection{Test response compactor}

In traditional testing approaches of digital circuits, the good circuit is tested by a digital signature, generated from the linear feedback shift register (LFSR) [3, 5, 7]. In addition, the single-shot circuit is tested by generating a digital signature based on the measurement of the time duration that expresses the proper functionality of the single-shot circuits [25]. In analogue circuits, the test response (TRC) function is design to generate a digital signature based on accumulation weighting sums of the sample magnitude of the analogue output response. These samples are generated from the ADC, and the required digital signature is generated from TRC by accumulating those samples. These samples are based on the analogue output response of the ACUT and the applied signal generated from ATPG. The schematic diagram of the TRC module, shown in Figure 9, is responsible for simulating the TRC scheme in the presented analogue testing. The generated signature from the TRC module can represent the analogue output response of the ACUT in the criteria of the ACUT judgment.

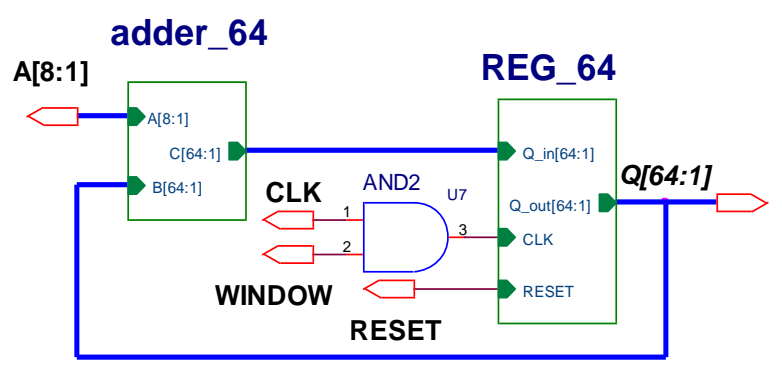

Fig 9: Schematic diagram of the TRC stage.

The TRC module has two main modules; 64-bit adder, and 64-bit register. The 64-bit adder is represented by module, ADDER_64, and the 64-bit register is represented by module REG_64. The adder accepts sample outputs of the ADC (A[8:1]) and outputs of the REG_64 (Q[64:1]), and produces the sum of them. After one clock shift (CLK, gated by control signal WINDOW, considered the test gate), the sum Q[64:1] is generated. The input clock of the 64-bit register, generated from CLK, is used to proper synchronization. The input data $\mathrm{A}[8: 1]$ to the TRC is processed every clock cycle within the gate interval control signal WINDOW. Using suitable triggering edges of the CLK, the synchronization and processing operation are achieved. The test gate can be controlled and generated for proper operation of the signature generation. The input clock of the 64-bit register is the gated clock inside the test gate. The control signal RESET is the signal that clears the REG_64 in the beginning of each test gate WINDOW. The TRC generates a digital signature after the test gate WINDOW is closed shown in Figure 10, and the input clock of the 64-bit register stops running.

Figure 11 illustrates the full timing waveform cycle of the presented testing approach for both analogue signals and digital signals. The analogue signals are the ATPG output V(ATPG_OUT), the bipolar ACUT output V(BPF_OUT), and the rectified output from the rectifier circuit V(RECTIFIER_OUT). The digital signals are the RESET, $\mathrm{S} / \mathrm{H}$, CLK, and WINDOW. In addition, the digital buses are $\mathrm{A}[8: 1], \mathrm{Q}[32: 1]$, and $\mathrm{Q}[64: 33]$. The accumulation process of the TRC module is triggered by the RESET signal to execute a number of iterations equals to the number of weighted samples. Figure 10 illustrates the timing of the digital signals that affect the TRC module in different time during the test cycle window. All control signals, presented in Figure 10 and Figure 11, are properly asserted in the start of the test gate, the middle of the test gate, and the end of the test gate to generate a digital signature.

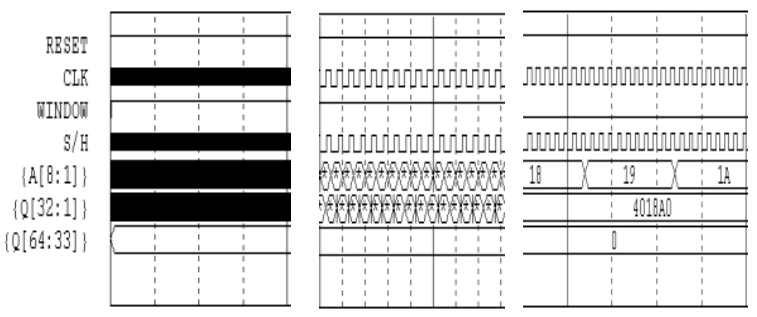

Fig 10: Timing diagram of the starting test gate, the middle test gate, and the closing test gate of the accumulation process. 


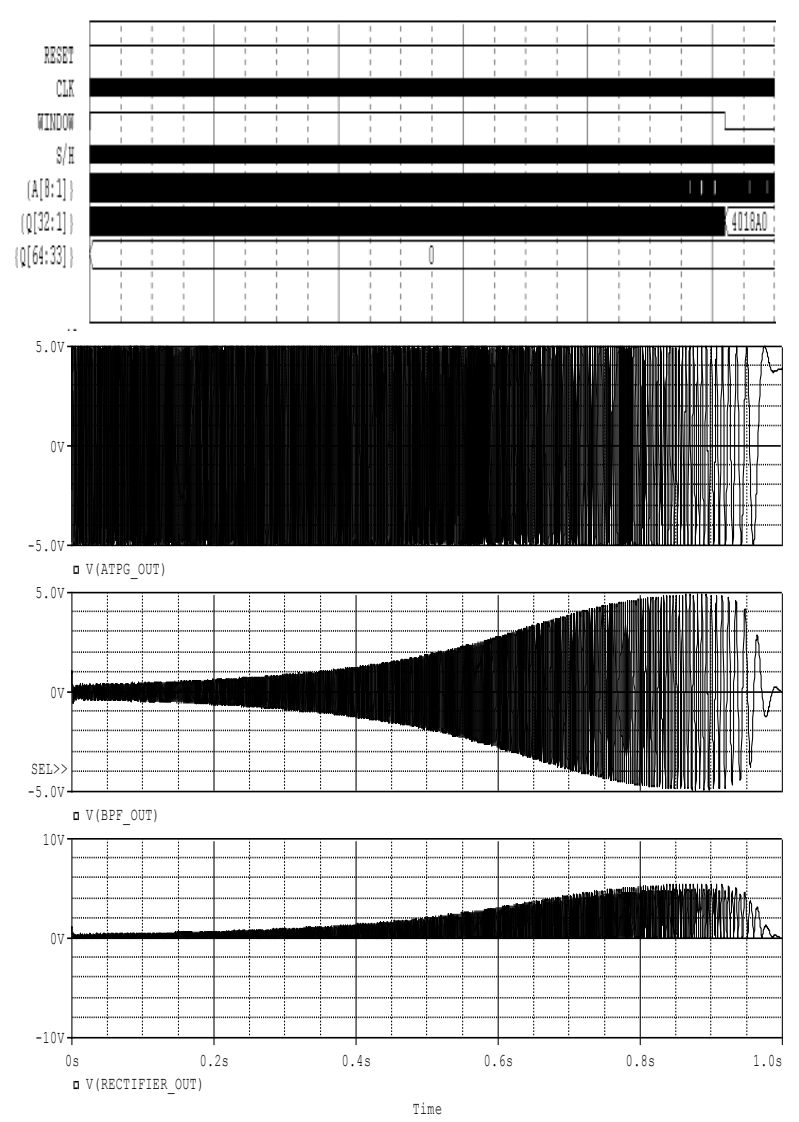

Fig 11: Full Timing diagram of the circuit model of the analogue testing.

\section{PSPICE CIRCUIT MODEL SIMULATION OF THE ACUT}

The modeling of ACUT transfer function is the main step to predict the output response of the ACUT. Analogue circuit differs by their characteristics and parameters that control its analogue response. These parameters have a great role in the process of predicting the fault-free output analogue response and accordingly improve the process of detecting different ACUT faults. The ACUT model selected from a group of standard analogue circuits called benchmark circuits [26]. Each benchmark circuit could be modeled through its transfer function in the frequency domain that requires a specified input sinusoidal signal swept in frequency.

The developed approach is verified and validated the decision for the ACUT in two major phases. The first phase is for a golden fault-free ACUT and the second phase is for predefined faults in the same ACUT. The presented testing approach determines an ACUT status in both cases based on the generated digital signature. The signature comparison is achieved based on the pre-calculated signature boundaries in the first phase. Signature boundaries are calculated from the analogue output response of the simulated ACUT model using the PSpice circuit simulator and based on the worst-case analysis of both the minimum and the maximum of the output analogue response of the ACUT. This boundary calculation considers the tolerances of ACUT components that affect the transfer function of the ACUT. If the calculated signature in the second phase lies within the pre-calculated signature boundaries, it judged as a fault-free ACUT, otherwise it judged as a faulty one. one of the benchmark circuits as an
ACUT is selected. This circuit is the band pass filter (BPF) in the frequency range of the biomedical circuits.

The schematic diagram of the BPF is shown in Figure 12. By a simple analysis, it is clarified that its transfer function and its transfer function coefficients are as follow:

$$
\mathrm{TF}=\frac{\mathrm{ab}}{\mathrm{s}^{5}+s^{4}\left(a_{2}+\mathrm{b}_{1}\right)+\mathrm{s}^{3}\left(a_{1}+a_{2} b_{1}+b\right)+s^{2}\left(a+a_{1} b_{1}+b\right)+s\left(a_{1}+a_{2} b\right)+a b}
$$

where,

$$
\begin{gathered}
\mathrm{a}=\frac{1}{\mathrm{C}_{1} \mathrm{C}_{2} \mathrm{C}_{3} \mathrm{R}_{1} \mathrm{R}_{2} \mathrm{R}_{3}} \quad \mathrm{~b}=\frac{1}{\mathrm{R}_{4} \mathrm{R}_{5} \mathrm{C}_{4} \mathrm{C}_{5}} \quad \mathrm{~b} 1=\frac{1}{\mathrm{R}_{5} \mathrm{C}_{4}}+\frac{1}{\mathrm{R}_{4} \mathrm{C}_{4}} \\
\mathrm{a} 1=\frac{1}{\mathrm{C}_{2} \mathrm{C}_{3} \mathrm{R}_{2} \mathrm{R}_{3}}+\frac{1}{\mathrm{C}_{1} \mathrm{C}_{2} \mathrm{R}_{2} \mathrm{R}_{3}}+\frac{1}{\mathrm{C}_{1} \mathrm{C}_{2} \mathrm{R}_{1} \mathrm{R}_{3}}+\frac{1}{\mathrm{C}_{1} \mathrm{C}_{2} \mathrm{R}_{1} \mathrm{R}_{2}} \\
\mathrm{a} 2=\frac{1}{\mathrm{C}_{1} \mathrm{R}_{1}}+\frac{1}{\mathrm{C}_{1} \mathrm{R}_{2}}+\frac{1}{\mathrm{C}_{2} \mathrm{R}_{3}}+\frac{1}{\mathrm{C}_{2} \mathrm{R}_{2}}
\end{gathered}
$$

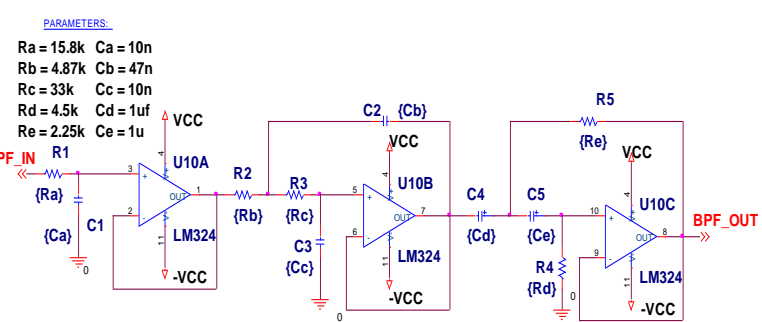

Fig 12: Schematic diagram of the BPF.

The worst-case analysis is used to find the worst-case probable output of an analogue circuit, given the circuit description, and the restricted parameter tolerances. It is the upper or lowest possible collating function relative to the nominal run. PSpice circuit simulator allows tolerances to be set on any number of the parameters that characterize a model. Models can be defined for nearly all primitive analogue circuit components (resistors, capacitors, semiconductor devices, etc). PSpice reads the standard model parameter tolerance, and uses the nominal, minimum, and maximum probable values. For instance, if the values of R1, R2, R3, R4, $\mathrm{R} 5, \mathrm{C} 1, \mathrm{C} 2, \mathrm{C} 3, \mathrm{C} 4$, and $\mathrm{C} 5$ in the case of BPF can vary by $\pm 5 \%, \pm 10 \%$, or $\pm 20 \%$, then the worst-case analysis will attempt to find the combination of possible resistor values and capacitor values which result in the worst simulated output. For the worst-case analysis, each component value is taken from its nominal as allowed by its tolerance, in the direction which should cause the collating function to be its worst (given by the upper or lowest specification).

A summary of that analysis is illustrated in Table 1 that shows the percent change corresponding to each component. For example, R1 equals 0.95 of nominal value for the lowest bound and equals 1.05 of nominal value for the upper bound. It indicates that resistor value decreases (D) by $-5 \%$ for the lower bound, and increases (I) by $+5 \%$ for the upper bound. In $\pm 10 \%$ tolerance, R1 increases (D) by $-10 \%$ for the lower bound, and decreases (I) by $+10 \%$ for the upper bound. In addition, Table 2 illustrates the signature boundaries in hexadecimal format, and the nominal and worst-case component values based on the worst-case analysis. For example, SL equals 255758 for the lowest signature bound and SU equals 31BE12 for the upper signature bound according to the listed component values and $\pm 10 \%$ component tolerance in Table 2 . In $\pm 5 \%$ component tolerance, SL equals 283038 and SU equals 2E4693. In this case study, the output signal frequency sweeps from $1.2 \mathrm{~Hz}$ to $1.5 \mathrm{kHz}$ according to Figure 6. 
Table 1. Component tolerances for the worst-case analysis of the BPF.

\begin{tabular}{|l|l|l|l|l|l|l|}
\hline \multirow{2}{*}{ Comp } & \multicolumn{2}{|c|}{ $\pm 5 \%$} & \multicolumn{2}{c|}{ $\pm 10 \%$} & \multicolumn{2}{c|}{ $\pm 20 \%$} \\
\cline { 2 - 7 } & LOWEST & UPPER & LOWEST & UPPER & LOWEST & UPPER \\
\hline R1 & $0.95(\mathrm{D})$ & $1.05(\mathrm{I})$ & $0.9(\mathrm{D})$ & $1.1(\mathrm{I})$ & $0.8(\mathrm{D})$ & $1.2(\mathrm{I})$ \\
\hline R2 & $1.05(\mathrm{I})$ & $0.95(\mathrm{D})$ & $1.1(\mathrm{I})$ & $0.9(\mathrm{D})$ & $1.2(\mathrm{I})$ & $0.8(\mathrm{D})$ \\
\hline R3 & $0.95(\mathrm{D})$ & $1.05(\mathrm{I})$ & $0.9(\mathrm{D})$ & $1.1(\mathrm{I})$ & $0.8(\mathrm{D})$ & $1.2(\mathrm{I})$ \\
\hline R4 & $1.05(\mathrm{I})$ & $0.95(\mathrm{D})$ & $1.1(\mathrm{I})$ & $0.9(\mathrm{D})$ & $1.2(\mathrm{I})$ & $0.8(\mathrm{D})$ \\
\hline R5 & $0.95(\mathrm{D})$ & $1.05(\mathrm{I})$ & $0.9(\mathrm{D})$ & $1.1(\mathrm{I})$ & $0.8(\mathrm{D})$ & $1.2(\mathrm{I})$ \\
\hline C1 & $0.95(\mathrm{D})$ & $1.05(\mathrm{I})$ & $0.9(\mathrm{D})$ & $1.1(\mathrm{I})$ & $0.8(\mathrm{D})$ & $1.2(\mathrm{I})$ \\
\hline C2 & $1.05(\mathrm{I})$ & $0.95(\mathrm{D})$ & $1.1(\mathrm{I})$ & $0.9(\mathrm{D})$ & $1.2(\mathrm{I})$ & $0.8(\mathrm{D})$ \\
\hline C3 & $0.95(\mathrm{D})$ & $1.05(\mathrm{I})$ & $0.9(\mathrm{D})$ & $1.1(\mathrm{I})$ & $0.8(\mathrm{D})$ & $1.2(\mathrm{I})$ \\
\hline C4 & $1.05(\mathrm{I})$ & $0.95(\mathrm{D})$ & $1.1(\mathrm{I})$ & $0.9(\mathrm{D})$ & $1.2(\mathrm{I})$ & $0.8(\mathrm{D})$ \\
\hline C5 & $1.05(\mathrm{I})$ & $0.95(\mathrm{D})$ & $1.1(\mathrm{I})$ & $0.9(\mathrm{D})$ & $1.2(\mathrm{I})$ & $0.8(\mathrm{D})$ \\
\hline
\end{tabular}

Table 2. Signature boundaries for the worst-case analysis of the BPF.

\begin{tabular}{|c|c|c|c|c|c|c|c|}
\hline \multirow{2}{*}{ Comp } & \multirow{2}{*}{ Nominal } & \multicolumn{2}{|l|}{ $\pm 5 \%$} & \multicolumn{2}{|l|}{ $\pm 10 \%$} & \multicolumn{2}{|l|}{ $\pm 20 \%$} \\
\hline & & LOWEST & UPPER & LOWEST & UPPER & LOWEST & UPPER \\
\hline $\mathrm{R} 1(\Omega)$ & $15.8 \mathrm{k}$ & $16.56 \mathrm{k}$ & $15.14 \mathrm{k}$ & $17.38 \mathrm{k}$ & $14.22 \mathrm{k}$ & $18.96 \mathrm{k}$ & $12.64 \mathrm{k}$ \\
\hline $\mathrm{R} 2(\Omega)$ & $4.87 \mathrm{k}$ & $4.6265 \mathrm{k}$ & $5.1135 \mathrm{k}$ & $4.383 \mathrm{k}$ & $5.357 \mathrm{k}$ & $3.896 \mathrm{k}$ & $5.844 \mathrm{k}$ \\
\hline $\mathrm{R} 3(\Omega)$ & $33 \mathrm{k}$ & $34.65 \mathrm{k}$ & $31.35 \mathrm{k}$ & $36.3 \mathrm{k}$ & $29.7 \mathrm{k}$ & $39.6 \mathrm{k}$ & $26.4 \mathrm{k}$ \\
\hline $\mathrm{R} 4(\Omega)$ & $4.5 \mathrm{k}$ & $4.275 \mathrm{k}$ & $4.725 \mathrm{k}$ & $4.05 \mathrm{k}$ & $4.95 \mathrm{k}$ & $3.6 \mathrm{k}$ & $5.4 \mathrm{k}$ \\
\hline R5 $(\Omega)$ & $2.25 \mathrm{k}$ & $2.3625 \mathrm{k}$ & $2.1375 \mathrm{k}$ & $2.475 \mathrm{k}$ & $2.025 \mathrm{k}$ & $2.7 \mathrm{k}$ & $1.8 \mathrm{k}$ \\
\hline C1 (F) & $10 \mathrm{n}$ & $10.5 n$ & $9.5 n$ & $11 n$ & $9 n$ & $12 n$ & $8 n$ \\
\hline C2 (F) & $47 n$ & $44.65 n$ & $49.35 n$ & $42.3 n$ & $51.7 \mathrm{n}$ & $37.6 n$ & $56.4 n$ \\
\hline C3 (F) & $10 \mathrm{n}$ & $10.5 n$ & $9.5 n$ & $11 n$ & $9 n$ & $12 n$ & $8 n$ \\
\hline C4 (F) & luf & $0.95 u$ & $1.05 \mathrm{u}$ & $0.9 \mathrm{u}$ & $1.1 \mathrm{u}$ & $0.8 \mathrm{u}$ & $1.2 \mathrm{u}$ \\
\hline \multirow[t]{4}{*}{ C5 (F) } & luf & $0.95 u$ & $1.05 \mathrm{u}$ & $0.9 \mathrm{u}$ & $1.1 \mathrm{u}$ & $0.8 \mathrm{u}$ & $1.2 \mathrm{u}$ \\
\hline & \multicolumn{7}{|c|}{ Digital Signatures } \\
\hline & SN & SL & $\mathrm{SU}$ & SL & SU & SL & SU \\
\hline & $2 \mathrm{~B} 29 \mathrm{CF}$ & 283038 & $2 \mathrm{E} 4693$ & 255758 & 31BE12 & 200BFD & $3960 \mathrm{E} 3$ \\
\hline
\end{tabular}

\section{PARAMTERIC FAULT ANALYSIS OF THE BAND PASS FILTER USING SIGNATURE CURVE}

In this section, the effect of the parametric fault of the component in the band pass filter, illustrated in Figure 12 is presented. The effects of all component variations in the ACUT with respect to the passband transmission $\left(A_{\max }\right)$ and the bandwidth $(B W)$ are taken in the consideration. According to the nominal values of the resistors and the capacitors presented in Figure 12 and the AC Analysis of the PSpice circuit simulator, the value of the bandwidth $(B W)$ equals 480 $\mathrm{Hz}$, and the $A_{\max }$ equals $0.98305 \mathrm{~V}$. This filter can be used in the extraction circuit of muscle potentials of EMG waveform to reject low signals besides the signals above $500 \mathrm{~Hz}$.

Component variations in this paper will sweep from very small value (or short circuit (SC) in the case of impedances), $\pm 10 \%, \pm 20 \%, \pm 50 \% \ldots$, until very large value (or open circuit (OC) in the case of impedances). Therefore, the effect of component variations on the BPF output response is achieved, and consequently the relation between the generated digital signatures with respect to component variations is required to be stated and analyzed. The derived curve is called the signature curve. The requirement of the signature curve combines the effect of the $A_{\max }$ and the $B W$ in one curve that illustrates the ACUT status.

The analysis of the output response based on the amplitude response of the BPF is done using the PSpice circuit simulator (AC Analysis). The amplitude response of the BPF based on each resistor variation $(R a, R b, R c, R d, R e)$ and each capacitor variation $(C a, C b, C c, C d, C e)$ is presented. The resistor variation is achieved from $1 \Omega(\mathrm{SC})$ to $10 \mathrm{M} \Omega(\mathrm{OC})$, and the capacitor variation is achieve from $1 p F$ (very small value) to $1 \mathrm{mF}$ (very large value). In Table 3 and Table 4, the $B W$ values, the $A_{\max }$, and the corresponding digital signatures with respect to each resistor variation and each capacitor variation is illustrated.

Table 3. Signatures, $B W$, and $A_{\max }$ for each resistor variations of the $B P F$.

\begin{tabular}{|c|c|c|c|c|c|c|}
\hline \multicolumn{3}{|c|}{ Component values } & $\boldsymbol{B} \boldsymbol{W}$ & $A_{\max }$ & $\begin{array}{c}\text { Sig. } \\
\text { (Hex.) }\end{array}$ & $\begin{array}{l}\text { Sig. } \\
\text { (Dec.) }\end{array}$ \\
\hline \multirow{18}{*}{$\begin{array}{l}R a \\
(\Omega)\end{array}$} & 1 & short & 544.750 & 0.996 & 313937 & 3225911 \\
\hline & 10 & & 544.750 & 0.996 & $31383 \mathrm{E}$ & 3225662 \\
\hline & 100 & & 544.746 & 0.996 & 3137FE & 3225598 \\
\hline & 1000 & & 544.398 & 0.996 & $312 \mathrm{~F} 1 \mathrm{C}$ & 3223324 \\
\hline & $7.9 \mathrm{k}$ & $-50 \%$ & 524.771 & 0.992 & 2F1F76 & 3088246 \\
\hline & 10000 & & 514.280 & 0.990 & 2E1F15 & 3022613 \\
\hline & 12640 & $-20 \%$ & 499.374 & 0.987 & 2CC916 & 2935062 \\
\hline & 14220 & $-10 \%$ & 489.847 & 0.985 & 2BF941 & 2881857 \\
\hline & $15.01 \mathrm{k}$ & $-5 \%$ & 484.971 & 0.984 & 2B91C6 & 2855366 \\
\hline & 15800 & NOM & 480.041 & 0.983 & 2B29CF & 2828751 \\
\hline & $16.59 \mathrm{k}$ & $+5 \%$ & 475.068 & 0.981 & 2AC3AD & 2802605 \\
\hline & 17380 & $+10 \%$ & 470.129 & 0.980 & 2A5DE2 & 2776546 \\
\hline & 18960 & $+20 \%$ & 460.010 & 0.978 & 299524 & 2725156 \\
\hline & $23.7 \mathrm{k}$ & $+50 \%$ & 429.996 & 0.971 & 275 A39 & 2579001 \\
\hline & 50000 & & 292.888 & 0.926 & 1E5067 & 1986663 \\
\hline & $1 \mathrm{E}+05$ & & 172.111 & 0.833 & $15 \mathrm{BF} 58$ & 1425240 \\
\hline & $1 \mathrm{E}+06$ & & 71.617 & 0.214 & 6B4BB & 439483 \\
\hline & $1 \mathrm{E}+07$ & open & 70.653 & 0.022 & $4 \mathrm{~A} 28 \mathrm{~A}$ & 303754 \\
\hline \multirow{18}{*}{$\begin{array}{l}R b \\
(\Omega)\end{array}$} & 1 & short & 397.099 & 0.948 & 2BCACE & 2869966 \\
\hline & 10 & & 397.390 & 0.948 & 2BCFD1 & 2871249 \\
\hline & 100 & & 400.307 & 0.949 & 2BFEBB & 2883259 \\
\hline & 1000 & & 430.060 & 0.954 & 2D5852 & 2971730 \\
\hline & 2435 & $-50 \%$ & 470.519 & 0.963 & 2D7B26 & 2980646 \\
\hline & 3896 & $-20 \%$ & 485.216 & 0.974 & $2 \mathrm{C} 3 \mathrm{~A} 6 \mathrm{E}$ & 2898542 \\
\hline & 4383 & $-10 \%$ & 483.797 & 0.978 & 2BB432 & 2864178 \\
\hline & 4626.5 & $-5 \%$ & 482.176 & 0.980 & 2B7070 & 2846832 \\
\hline & 4870 & NOM & 480.041 & 0.983 & 2B29CF & 2828751 \\
\hline & 5113.5 & $+5 \%$ & 477.455 & 0.985 & 2AE414 & 2810900 \\
\hline & 5357 & $+10 \%$ & 474.476 & 0.987 & 2A9D56 & 2792790 \\
\hline & 5844 & $+20 \%$ & 467.536 & 0.993 & 2A1116 & 2756886 \\
\hline & 7305 & $+50 \%$ & 441.650 & 1.013 & $28781 \mathrm{~F}$ & 2652191 \\
\hline & 10000 & & 391.138 & 1.059 & 25D1AE & 2478510 \\
\hline & 50000 & & 154.850 & 1.179 & 156A95 & 1403541 \\
\hline & $1 \mathrm{E}+05$ & & 100.820 & 1.050 & F62C1 & 1008321 \\
\hline & $1 \mathrm{E}+06$ & & 54.927 & 0.417 & 5CDDB & 380379 \\
\hline & $1 \mathrm{E}+07$ & open & 56.709 & 0.214 & 49CC9 & 302281 \\
\hline \multirow{18}{*}{$\begin{array}{l}R c \\
(\Omega)\end{array}$} & 1 & short & 911.197 & 0.980 & $43583 \mathrm{E}$ & 4413502 \\
\hline & 10 & & 912.116 & 0.980 & 435E92 & 4415124 \\
\hline & 100 & & 921.465 & 0.981 & 439FAF & 4431791 \\
\hline & 1000 & & 1034.256 & 0.982 & 462CDD & 4599005 \\
\hline & 10000 & & 998.997 & 0.996 & 450981 & 4524417 \\
\hline & 16500 & $-50 \%$ & 764.593 & 1.002 & 3AD089 & 3854473 \\
\hline & 26400 & $-20 \%$ & 565.812 & 0.992 & $301 \mathrm{BCD}$ & 3152845 \\
\hline & 29700 & $-10 \%$ & 524.953 & 0.988 & 2D7967 & 2980199 \\
\hline & 31.350 & $-5 \%$ & 499.177 & 0.985 & 2C48B5 & 2902197 \\
\hline & 33000 & NOM & 480.041 & 0.983 & 2B29CF & 2828751 \\
\hline & 34650 & $+5 \%$ & 462.186 & 0.980 & $2 \mathrm{~A} 1 \mathrm{CC} 3$ & 2759875 \\
\hline & 36300 & $+10 \%$ & 445.493 & 0.978 & 291EE4 & 2694884 \\
\hline & 39600 & $+20 \%$ & 415.183 & 0.972 & $274 C 68$ & 2575464 \\
\hline & 50000 & $+50 \%$ & 340.436 & 0.955 & 22A7E1 & 2271201 \\
\hline & 66000 & $-50 \%$ & 265.333 & 0.927 & 1DA0F1 & 1941745 \\
\hline & $1 \mathrm{E}+05$ & & 182.619 & 0.863 & 172FF7 & 1519607 \\
\hline & $1 \mathrm{E}+06$ & & 70.395 & 0.217 & $6 \mathrm{~A} 2 \mathrm{AC}$ & 434860 \\
\hline & $1 \mathrm{E}+07$ & open & 69.553 & 0.022 & $4 \mathrm{~A} 0 \mathrm{E} 8$ & 4413502 \\
\hline \multirow{18}{*}{$\begin{array}{l}R d \\
(\Omega)\end{array}$} & 1 & short & 625.467 & 0.001 & $48 \mathrm{D} 8 \mathrm{C}$ & 298380 \\
\hline & 10 & & 625.294 & 0.011 & $49 \mathrm{CDE}$ & 302302 \\
\hline & 100 & & 609.807 & 0.115 & 9E104 & 647428 \\
\hline & 1000 & & 475.219 & 0.702 & 21149D & 2167965 \\
\hline & 2250 & $-50 \%$ & 476.635 & 0.891 & $27 \mathrm{C} 3 \mathrm{BB}$ & 2606011 \\
\hline & 3600 & $-20 \%$ & 481.081 & 0.957 & 2A97A2 & 2791330 \\
\hline & 4050 & $-10 \%$ & 480.997 & 0.970 & 2AC1E4 & 2802148 \\
\hline & 4275 & $-5 \%$ & 480.640 & 0.977 & $2 \mathrm{AF} 85 \mathrm{~F}$ & 2816095 \\
\hline & 4500 & NOM & 480.041 & 0.983 & 2B29CF & 2828751 \\
\hline & 4725 & $+5 \%$ & 479.159 & 0.989 & 2B587F & 2840703 \\
\hline & 4950 & $+10 \%$ & 477.943 & 0.995 & 2BC624 & 2868772 \\
\hline & 5400 & $+20 \%$ & 474.340 & 1.008 & 2C0C19 & 2886681 \\
\hline & 9000 & $+50 \%$ & 407.857 & 1.151 & 2D252B & 2958635 \\
\hline & 10000 & & 383.089 & 1.194 & 2D5888 & 2971784 \\
\hline & 50000 & & 8.302 & 2.400 & 2E181D & 3020829 \\
\hline & $1 \mathrm{E}+05$ & & 3.615 & 3.344 & 2DBF30 & 2998064 \\
\hline & $1 \mathrm{E}+06$ & & 0.345 & 9.826 & 2EE8FA & 3074298 \\
\hline & $1 \mathrm{E}+07$ & open & 0.055 & 19.250 & 318DDA & 3247578 \\
\hline
\end{tabular}




\begin{tabular}{|c|c|c|c|c|c|c|}
\hline \multicolumn{3}{|c|}{ Component values } & $B W$ & $A_{\max }$ & $\begin{array}{c}\text { Sig. } \\
\text { (Hex.) }\end{array}$ & $\begin{array}{l}\text { Sig. } \\
\text { (Dec.) }\end{array}$ \\
\hline \multirow{18}{*}{$\begin{array}{l}R e \\
(\Omega)\end{array}$} & 1 & short & 99.858 & 0.549 & $306 \mathrm{FC} 9$ & 3174345 \\
\hline & 10 & & 71.583 & 4.332 & $306 \mathrm{FC} 9$ & 3174345 \\
\hline & 100 & & 77.590 & 3.248 & 371D36 & 3611958 \\
\hline & 1000 & & 357.516 & 1.196 & 2C734D & 2913101 \\
\hline & 1125 & $-50 \%$ & 385.893 & 1.148 & 2C $37 \mathrm{~F} 0$ & 2897904 \\
\hline & 1800 & $-20 \%$ & 463.351 & 1.013 & 2B7478 & 2847864 \\
\hline & 2025 & $-10 \%$ & 473.639 & 0.994 & $2 \mathrm{~B} 4 \mathrm{BFD}$ & 2837501 \\
\hline & 2137.5 & $-5 \%$ & 477.208 & 0.988 & 2B3A52 & 2832978 \\
\hline & 2250 & NOM & 480.041 & 0.983 & $2 \mathrm{~B} 29 \mathrm{CF}$ & 2828751 \\
\hline & 2362.5 & $+5 \%$ & 482.320 & 0.978 & $2 \mathrm{~B} 1 \mathrm{~B} 02$ & 2824962 \\
\hline & 2475 & $+10 \%$ & 484.184 & 0.975 & 2B0D0A & 2821386 \\
\hline & 2700 & $+20 \%$ & 487.022 & 0.969 & $2 \mathrm{AF} 409$ & 2814985 \\
\hline & 4500 & $+50 \%$ & 494.223 & 0.949 & $2 \mathrm{~A} 7943$ & 2783555 \\
\hline & 10000 & & 494.727 & 0.936 & $2 \mathrm{~A} 0 \mathrm{~F} 92$ & 2756498 \\
\hline & 50000 & & 493.471 & 0.928 & $29 \mathrm{ABAA}$ & 2730922 \\
\hline & $1 \mathrm{E}+05$ & & 493.270 & 0.927 & 299D47 & 2727239 \\
\hline & $1 \mathrm{E}+06$ & & 493.104 & 0.926 & 298D43 & 2723139 \\
\hline & $1 E+07$ & & 493.083 & 0.926 & & \\
\hline
\end{tabular}

Discussion and comments: Figure 13 and Figure 14 illustrate the signatures with respect to $R a, R b, R c, R d$, and $R e$ variations, called the signature curve of $R a, R b, R c, R d$, and $R e$. In addition, Figure 15 and Figure 16 illustrate the signatures with respect to $C a, C b, C c, C d$, and $C e$ variations, called the signature curve of $\mathrm{Ca}, \mathrm{Cb}, \mathrm{Cc}, \mathrm{Cd}$, and $\mathrm{Ce}$. During $R a, R b$, and $R c$ variations, the variation of $A_{\max }$ is nearly unity gain. The signature curves of $R a, R b$, and $R c$, illustrated in Figure 13, clearly have the same corresponding variations of $B W$, illustrated in Table 3. In these cases, the signature curves are affected with the $B W$, while it is not affected with the $A_{\max }$.

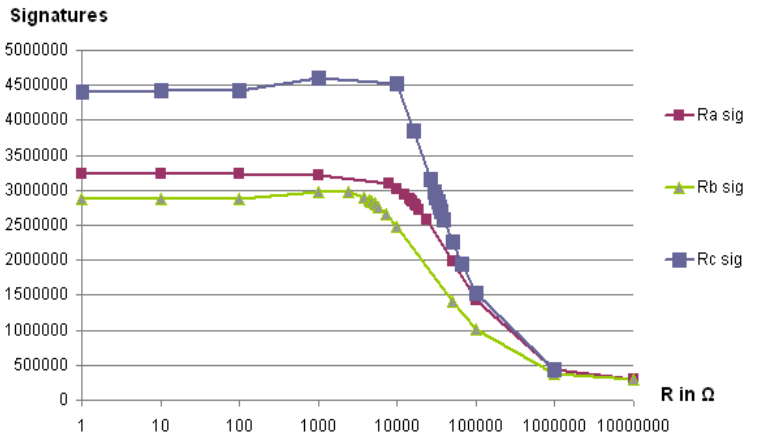

Fig 13: Signature curves of resistors $R a, R b$, and $R c$ in BPF.

During $R d$ variation, the signature curve is affected with both the variation of the $B W$ and the variation of the $A_{\max }$. During $R d$ variation from $1 \Omega$ to $100 \Omega$, the variation of $A_{\max }$ is low with very low gain below $0.115 \mathrm{~V} / \mathrm{V}$, and in the same time the variation of $B W$ is nearly constant with maximum $B W$. Therefore, the signatures illustrated in Figure 14 have small values due to low gain of the BPF that makes low values of output samples. During $R d$ variation from $100 \Omega$ to $10 \mathrm{k} \Omega$, the variation of $A_{\max }$ is increasing, and in the same time the variation of $B W$ is slowly decreasing. Therefore, the signature variation, illustrated in Figure 14, is increasing. During $R d$ variation from $1 \mathrm{k} \Omega$ to $1 \mathrm{M} \Omega$, the variation of $A_{\max }$ is increasing, and in the same time the variation of $B W$ is largely decreasing. Therefore, the signature variation, illustrated in Figure 14, is nearly constant according to the signature curve. During $R d$ variation from $1 \mathrm{M} \Omega$ to $10 \mathrm{M} \Omega$, the variation of $A_{\max }$ is largely increasing, and in the same time the variation of $B W$ is also largely decreasing. The signature variation, illustrated in Figure 14, is slowly increasing in the signature curve.

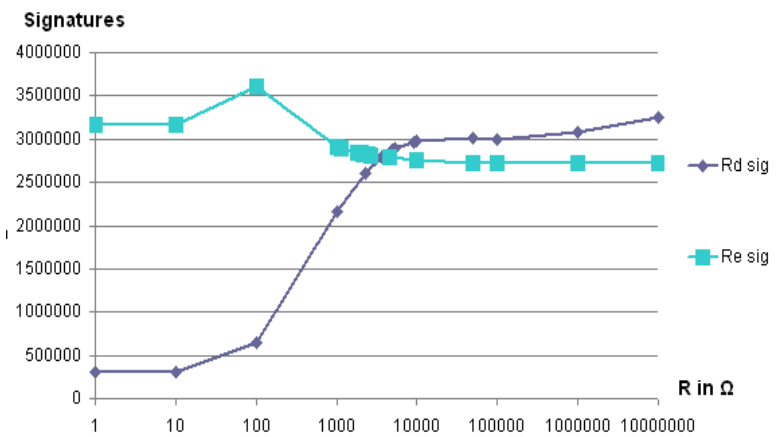

Fig 14: Signature curves of resistors $R d$, and $R e$ in BPF.

During $R e$ variation, the signature curve is affected with both the variation of the $B W$ and the variation of the $A_{\max }$. During $R e$ variation from $1 \Omega$ to $10 \Omega$, the variation of $A_{\max }$ is largely increasing, and in the same time the variation of $B W$ is slowly decreasing with the minimum $B W$. Therefore, the signature variation, illustrated in Figure 14, is nearly constant. During Re variation from $10 \Omega$ to $100 \Omega$, the variation of $A_{\max }$ is decreasing, and in the same time the variation of $B W$ is slowly increasing. Therefore, the signature variation, illustrated in Figure 14, is slowly increasing. During $R e$ variation from $100 \Omega$ to $-20 \%$ of the nominal value $(R e=2.25 \mathrm{k} \Omega)$, the variation of $A_{\max }$ is decreasing, and in the same time the variation of $B W$ is largely increasing. Therefore, the signature variation, illustrated in Figure 14, is slowly decreasing. During $R e$ variation from $-20 \%$ of the nominal value $(R e=$ $2.25 \mathrm{k} \Omega$ ) to $10 \mathrm{M} \Omega$, the variation of $A_{\max }$ is nearly constant with unity gain, and in the same time the variation of $B W$ is nearly constant with the maximum value of $B W$. Therefore, the signature variation, illustrated in Figure 14, is nearly constant.

Table 4. Signatures, $B W$, and $A_{\max }$ for each capacitor variations of the $B P F$.

\begin{tabular}{|c|c|c|c|c|c|c|}
\hline \multicolumn{3}{|c|}{ Component values } & \multirow{2}{*}{$\frac{B \boldsymbol{W}}{544.750}$} & \multirow{2}{*}{$\begin{array}{c}\boldsymbol{A}_{\max } \\
0.996\end{array}$} & \multirow{2}{*}{$\begin{array}{l}\text { Sig. } \\
\text { (Hex.) } \\
313941\end{array}$} & \multirow{2}{*}{$\begin{array}{l}\text { Sig. } \\
\text { (Dec.) } \\
3225921\end{array}$} \\
\hline \multirow{18}{*}{$\begin{array}{l}\mathrm{Ca} \\
(\mathrm{pF})\end{array}$} & 1 & open & & & & \\
\hline & 10 & & 544.749 & 0.996 & $31394 \mathrm{E}$ & 3225934 \\
\hline & 100 & & 544.741 & 0.996 & $31387 \mathrm{E}$ & 3225726 \\
\hline & 1000 & & 543.875 & 0.996 & 312050 & 3219536 \\
\hline & 5000 & $-50 \%$ & 524.770 & 0.992 & 2F1F52 & 3088210 \\
\hline & 8000 & $-20 \%$ & 499.374 & 0.987 & $2 \mathrm{CC} 900$ & 2935040 \\
\hline & 9000 & $-10 \%$ & 489.847 & 0.985 & 2BF923 & 2881827 \\
\hline & 9500 & $-5 \%$ & 484.971 & 0.984 & 2B91BC & 2855356 \\
\hline & 10000 & NOM & 480.041 & 0.983 & 2B29CF & 2828751 \\
\hline & 10500 & $+5 \%$ & 475.068 & 0.981 & 2AC3A9 & 2802601 \\
\hline & 11000 & $+10 \%$ & 470.065 & 0.980 & 2A5DF3 & 2776563 \\
\hline & 12000 & $+20 \%$ & 460.010 & 0.978 & 299553 & 2725203 \\
\hline & 15000 & $+50 \%$ & 429.996 & 0.971 & $275 \mathrm{~A} 61$ & 2579041 \\
\hline & $1 \mathrm{E}+05$ & & 123.866 & 0.732 & $10 \mathrm{~F} 11 \mathrm{~A}$ & 1110298 \\
\hline & $1 \mathrm{E}+06$ & & 72.5738 & 0.265 & 5D16A & 381290 \\
\hline & $5 \mathrm{E}+07$ & & 70.8697 & 0.139 & $491 \mathrm{CD}$ & 299469 \\
\hline & $1 \mathrm{E}+08$ & & 70.6536 & 0.001 & 491CD & 299469 \\
\hline & $1 \mathrm{E}+09$ & short & 70.653 & 0.0001 & $491 C D$ & 299469 \\
\hline \multirow{15}{*}{$\begin{array}{l}\mathrm{Cb} \\
\text { (pF) }\end{array}$} & 1 & open & 358.661 & 0.940 & 293424 & 2700324 \\
\hline & 10 & & 358.688 & 0.940 & 2934BC & 2700476 \\
\hline & 100 & & 358.961 & 0.940 & 2939C9 & 2701769 \\
\hline & 1000 & & 361.708 & 0.941 & 2968ED & 2713837 \\
\hline & 10000 & & 391.138 & 0.947 & 2AF234 & 2814516 \\
\hline & 23500 & $-50 \%$ & 437.646 & 0.958 & 2BE320 & 2876192 \\
\hline & 37600 & $-20 \%$ & 472.299 & 0.972 & 2BA39B & 2859931 \\
\hline & 42300 & $-10 \%$ & 477.734 & 0.977 & 2B6B09 & 2845449 \\
\hline & 45825 & $-5 \%$ & 479.742 & 0.981 & 2B3B3F & 2833215 \\
\hline & 47000 & $\mathrm{NOM}$ & 480.041 & 0.983 & 2B29CF & 2828751 \\
\hline & 48175 & $+5 \%$ & 480.162 & 0.984 & 2B1965 & 2824549 \\
\hline & 51700 & $+10 \%$ & 479.509 & 0.989 & 2AE31E & 2810654 \\
\hline & 56400 & $+20 \%$ & 476.409 & 0.998 & $2 \mathrm{~A} 983 \mathrm{E}$ & 2791486 \\
\hline & 94000 & $+50 \%$ & 405.909 & 1.127 & 283585 & 2635141 \\
\hline & $1 \mathrm{E}+05$ & & 393.520 & 1.152 & 27DA7E & 2611838 \\
\hline
\end{tabular}




\begin{tabular}{|c|c|c|c|c|c|c|}
\hline \multicolumn{3}{|c|}{ Component values } & \multirow{2}{*}{$\begin{array}{l}\boldsymbol{B} \boldsymbol{W} \\
38.047\end{array}$} & \multirow{2}{*}{$\begin{array}{l}A_{\max } \\
3.298 \\
\end{array}$} & \multirow{2}{*}{$\begin{array}{l}\begin{array}{l}\text { Sig. } \\
\text { (Hex.) }\end{array} \\
16 \text { EB552 }\end{array}$} & \multirow{2}{*}{$\begin{array}{l}\begin{array}{l}\text { Sig. } \\
\text { (Dec.) }\end{array} \\
1502034\end{array}$} \\
\hline & $1 \mathrm{E}+06$ & & & & & \\
\hline & $5 \mathrm{E}+07$ & & 0.914 & 2.424 & 53357 & 340823 \\
\hline & $1 \mathrm{E}+08$ & & 0.539 & 1.461 & 4D00D & 315405 \\
\hline & $1 \mathrm{E}+09$ & short & 0.202 & 0.123 & 491D0 & 299472 \\
\hline \multirow{18}{*}{$\begin{array}{l}C c \\
(\mathrm{pF})\end{array}$} & 1 & open & 400.216 & 1.277 & 45657D & 4547965 \\
\hline & 10 & & 702.234 & 1.429 & $4585 \mathrm{E} 6$ & 4556262 \\
\hline & 100 & & 396.392 & 1.286 & 46D83D & 4642877 \\
\hline & 1000 & & 1950.75 & 1.198 & 580198 & 5767576 \\
\hline & 5000 & $-50 \%$ & 811.094 & 1.037 & 3E48B9 & 4081849 \\
\hline & 8000 & $-20 \%$ & 580.018 & 0.996 & 30DFF3 & 3203059 \\
\hline & 9000 & $-10 \%$ & 26.039 & 0.989 & $2 \mathrm{DCCA} 2$ & 3001506 \\
\hline & 9500 & $-5 \%$ & 502.142 & 0.986 & 2C6EDF & 2911967 \\
\hline & 10000 & NOM & 480.041 & 0.983 & $2 \mathrm{~B} 29 \mathrm{CF}$ & 2828751 \\
\hline & 10500 & $+5 \%$ & 459.562 & 0.979 & $29 \mathrm{FB} 70$ & 2751344 \\
\hline & 11000 & $+10 \%$ & 440.553 & 0.976 & $28 \mathrm{E} 084$ & 2678917 \\
\hline & 12000 & $+20 \%$ & 406.419 & 0.970 & 26DD62 & 2547042 \\
\hline & 15000 & $+50 \%$ & 327.958 & 0.950 & $220 \mathrm{FB} 9$ & 2232249 \\
\hline & $1 \mathrm{E}+05$ & & 81.52 & 0.486 & A9FF1 & 696305 \\
\hline & $1 \mathrm{E}+06$ & & 69.787 & 0.059 & 4EF8E & 323470 \\
\hline & $5 \mathrm{E}+07$ & & 69.712 & 0.001 & 491D0 & 299472 \\
\hline & $1 \mathrm{E}+08$ & & 69.716 & 0.0006 & 491D0 & 299472 \\
\hline & $1 \mathrm{E}+09$ & short & 69.715 & $5.914 \mathrm{E}-5$ & 491D0 & 299472 \\
\hline \multirow{17}{*}{$\begin{array}{l}C d \\
(\mathrm{pF})\end{array}$} & 1 & open & 623.610 & $1 \mathrm{E}-5$ & 491D0 & 299472 \\
\hline & 10 & & 623.610 & 0.0001 & 491D0 & 299472 \\
\hline & 100 & & 623.606 & 0.001 & 491D0 & 299472 \\
\hline & 1000 & & 623.445 & 0.01 & 490F5 & 299253 \\
\hline & 100000 & & 469.990 & 0.956 & 1 F7930 & 2062640 \\
\hline & 500000 & $-50 \%$ & 476.293 & 0.978 & $29 \mathrm{C} 313$ & 2736915 \\
\hline & 800000 & $-20 \%$ & 478.205 & 0.981 & 2AD6D0 & 2807504 \\
\hline & 900000 & $-10 \%$ & 479.133 & 0.982 & $2 \mathrm{~B} 05 \mathrm{C} 7$ & 2819527 \\
\hline & 950000 & $-5 \%$ & 480.041 & 0.983 & $2 \mathrm{~B} 1910$ & 2824464 \\
\hline & $1 \mathrm{E}+06$ & NOM & 80.928 & 0.983 & $2 \mathrm{~B} 29 \mathrm{CF}$ & 2828751 \\
\hline & 1050000 & $+5 \%$ & 481.794 & 0.984 & $2 \mathrm{~B} 38 \mathrm{~F} 0$ & 2832624 \\
\hline & $11 \mathrm{E}+05$ & $+10 \%$ & 483.457 & 0.984 & 2B4737 & 2836279 \\
\hline & $12 \mathrm{E}+05$ & $+20 \%$ & 487.855 & 0.983 & 2B5CF0 & 2841840 \\
\hline & $15 \mathrm{E}+05$ & $+50 \%$ & 70.954 & 0.664 & 2B890D & 2853133 \\
\hline & $5 \mathrm{E}+07$ & & 469.990 & 0.956 & 2B5A3B & 2841147 \\
\hline & $1 \mathrm{E}+08$ & & 480.041 & 0.983 & 2B4F38 & 2838328 \\
\hline & $1 \mathrm{E}+09$ & short & 504.723 & 0.966 & 2B4748 & 2836296 \\
\hline \multirow{17}{*}{$\begin{array}{l}\mathrm{Ce} \\
\text { (pF) }\end{array}$} & 1 & open & 623.626 & $1.85 \mathrm{E}-05$ & 491D0 & 299472 \\
\hline & 10 & & 623.605 & 0.0001 & 491D0 & 299472 \\
\hline & 100 & & 623.603 & 0.001 & 491D0 & 299472 \\
\hline & 1000 & & 623.458 & 0.01 & 490F5 & 299253 \\
\hline & $1 \mathrm{E}+05$ & & 470.943 & 0.665 & 1F7930 & 2062640 \\
\hline & $5 \mathrm{E}+05$ & $-50 \%$ & 469.978 & 0.956 & $29 \mathrm{C} 313$ & 2736915 \\
\hline & $8 \mathrm{E}+05$ & $-20 \%$ & 476.289 & 0.979 & 2AD6D0 & 2807504 \\
\hline & $9 \mathrm{E}+05$ & $-10 \%$ & 478.203 & 0.981 & $2 \mathrm{~B} 05 \mathrm{C} 7$ & 2819527 \\
\hline & $95 \mathrm{E}+04$ & $-5 \%$ & 479.132 & 0.982 & 2B1910 & 2824464 \\
\hline & $1 \mathrm{E}+06$ & NOM & 480.041 & 0.983 & $2 \mathrm{~B} 29 \mathrm{CF}$ & 2828751 \\
\hline & 1050000 & $+5 \%$ & 480.929 & 0.984 & $2 \mathrm{~B} 38 \mathrm{~F} 0$ & 2832624 \\
\hline & $11 \mathrm{E}+05$ & $+10 \%$ & 481.796 & 0.984 & 2B4737 & 2836279 \\
\hline & $12 \mathrm{E}+05$ & $+20 \%$ & 483.461 & 0.984 & 2B5CF0 & 2841840 \\
\hline & $15 \mathrm{E}+05$ & $+50 \%$ & 487.861 & 0.984 & 2B890D & 2853133 \\
\hline & $5 \mathrm{E}+07$ & & 480.041 & 0.983 & $2 \mathrm{~B} 5 \mathrm{~A} 3 \mathrm{~B}$ & 2841147 \\
\hline & $1 \mathrm{E}+08$ & & 504.715 & 0.966 & 2B4F38 & 2838328 \\
\hline & $1 \mathrm{E}+09$ & short & 504.601 & 0.965 & 2B 4748 & 2836296 \\
\hline
\end{tabular}

Discussion and comments: During $\mathrm{Ca}$ variation, the variation of $A_{\max }$ is nearly unity gain from $1 p F$ to $1 \mu F$, and is decreasing from $1 \mu F$ to $1 \mathrm{mF}$. The signature variation of $C a$ clearly has the same corresponding variation of $B W$. In this case, the signature curve, illustrated in Figure 15, is affected with the $B W$.

During $C b$ variation, the variation of $A_{\max }$ is nearly unity gain from $1 p F$ to $0.1 \mu F$, is increasing from $0.1 \mu F$ to $1 \mu F$, and is decreasing from $1 \mu F$ to $1 \mathrm{mF}$. The signature variation of $C b$ clearly has the same corresponding variation of $B W$. In this case, the signature curve, illustrated in Figure 15, is affected with the $B W$. Large values of $A_{\max }$ during $C b$ variation from $0.1 \mu F$ to $1 \mathrm{mF}$ cannot affect the signature values due to very low $B W$ values.

During $C c$ variation, the variation of $A_{\max }$ is nearly unity gain from $1 p F$ to $15 n F$, and is decreasing from $15 n F$ to $1 \mu F$. In addition, the variation of $A_{\max }$ is very low gain from $1 \mu F$ to
$1 \mathrm{mF}$. In this case and during $C c$ variation, the signature curve is affected with both the variation of the $B W$ and the variation of the $A_{\max }$. During $C c$ variation from $1 p F$ and $1 n F$, the variation of $A_{\max }$ is nearly unity gain, and in the same time small irregular variation of $B W$ during $C c$ variation from $1 p F$ and $100 \mathrm{pF}$, and increasing variation of $B W$ during $C c$ variation from $100 p F$ and $1 n F$. Therefore, the signature variation is constant from $1 p F$ and $100 p F$, and is increasing from $100 \mathrm{pF}$ and $1 n F$, illustrated in Figure 15. During $C c$ variation from $1 n F$ to $1 \mu F$, the variation of $A_{\max }$ is slowly decreasing, and in the same time the variation of $B W$ is largely decreasing. Therefore, the signature variation, illustrated in Figure 15, has the same corresponding variation of $B W$. During $C c$ variation from $1 \mu F$ and $1 \mathrm{mF}$, the variation of $A_{\max }$ is low with very low gain, and in the same time the variation of $B W$ is constant with low values of $B W$. Therefore, the signature variation, illustrated in Figure 15, is nearly constant with the low signature values in the signature curve.

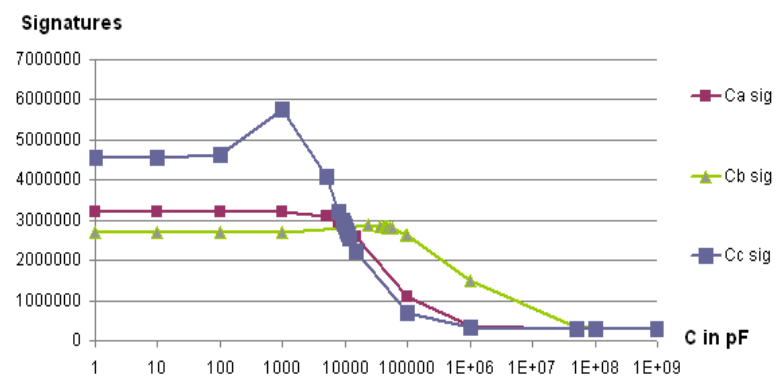

Fig 15: Signature curves of capacitors $C a, C b$, and $C c$ in BPF.

During $C d$ variation and $C e$ variation, the variation of $B W$ is nearly fluctuating above and below the nominal $B W$. The signature variations of $C d$ and $C e$ clearly have the same corresponding variation of $A_{\max }$. In this case, both coincident signature curves, illustrated in Figure 16, are affected with the $A_{\max }$.

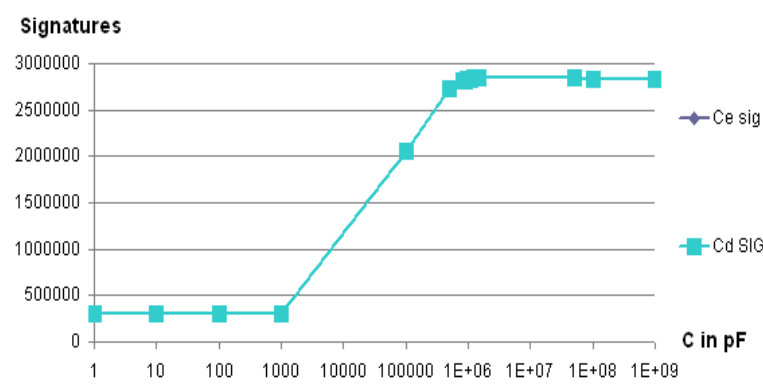

Fig 16: Signature curves of capacitors $C d$, and $C e$ in BPF.

In general, the signature curve is affected with the $B W$, while it is not affected by the $A_{\max }$ due to its constant variation. When the $B W$ has large values, the number of generated samples and their accumulation are large values. Therefore, the signature curve will be affected by the $B W$. In the other cases, the signature curve is affected with the $A_{\max }$, while it is not affected by the $B W$ due to its constant variation. When the $A_{\max }$ has large values, the number of generated samples and their accumulation are large values. Therefore, the signature curve will be affected by the $A_{\max }$. In the other cases, the signature curve is affected with the $B W$, and the $A_{\max }$. In this case, the large values of $B W$ and small values of the $A_{\max }$ due to the attenuation of the transfer function of the ACUT. Therefore, the digital accumulated signatures in the signature curve have small values due to the small values of the output 
samples. In addition, small values of the $B W$ and the constant variation of the $A_{\max }$ produce small values of the digital accumulated signatures in the signature curve due to small values of the output samples.

\section{CONCLUSION}

This paper presented the new testing approach of analogue circuits for detecting parametric faults based on the simulation environment. The proper ATPG that matches the frequency domain of the ACUT and the ATRC that generates a digital signature are achieved. The ATPG generates the required stimulation for the ACUT in the frequency sweep manner. Control signals are used to synchronize the ATPG and ATRC for digital signature generation based on accumulation weighting sums of the sample magnitude of the analogue output response. Component tolerances of the ACUT affect the transfer function of the ACUT. Therefore, the signature comparison is achieved based on signature boundaries, calculated from the worst-case analysis in PSpice circuit simulator for the ACUT judgment. In this paper, the presented testing approach enables the concept of the signature curve of each component of the ACUT. Based on this curve, the relation between digital signatures and component variations of the ACUT combines the effects of the bandwidth (BW) and the passband transmission (Amax) on the output response of the ACUT during component variations. In some cases, the signature curve is affected with the bandwidth only during the constant variation of Amax. In some other cases, the signature curve is affected with the Amax only during the constant variation of bandwidth. In other cases, the signature curve is affected with both the bandwidth and the Amax.

The presented testing approach is applied to a benchmark analogue circuit. The signature curves for that ACUT were determined. The proper decision is taken when the input signal has the frequency sweep manner contrary to the previously published work that states that the suitable input signal type for the ACUT was the pulse waveform. In the future work, the development of a low-cost ATE for testing of analogue circuits is highly required.

\section{REFERENCES}

[1] Mohamed H. El-Mahlawy, E. A. El-Sehely, A. S. Ragab, and S. Anas, "Design and Implementation of a New Built-In Self-Test Boundary Scan Architecture," Proceedings of the IEEE $15^{\text {th }}$ International conference on Microelectronics, $\mathrm{pp}$. 27-31, Cairo, Egypt, 2003.

[2] Mohamed H. El-Mahlawy, S. Anas, E. A. El-Sehely, and A. S. Ragab, "New Automatic Testing Architecture For Integrated Circuits," Proceedings of the $5^{\text {th }}$ International Conference of the Electrical Engineering (ICEENG), Military Technical College, Cairo, Egypt, 2006.

[3] Mohamed H. El-Mahlawy and A. Seddik, "Design and Implementation of New Automatic Testing System for Digital Circuits Based on the Signature Analysis," Proceedings of the $12^{\text {th }}$ International Conference on Aerospace Sciences \& Aviation Technology (ASAT), Military Technical College, Cairo, Egypt, 2007.

[4] Mohamed H. El-Mahlawy and E. H. Khalil, "A New Delay Built-In Self-Test Architecture Using Boundary Scan in Synchronous Mode," Proceedings of the $12^{\text {th }}$ International Conference on Aerospace Sciences \& Aviation Technology (ASAT), pp. 29-31, Military Technical College, Cairo, Egypt, 2007.
[5] Mohamed H. El-Mahlawy, A. Abd El-Wahab, and A.S. Ragab, "FPGA Implementation of The Portable Automatic Testing System for Digital Circuits," Proceedings of the $6^{\text {th }}$ International Conference of the Electrical Engineering (ICEENG), Military Technical College, Cairo, Egypt, 2008.

[6] Mihalis Psarakis, Dimitris Gizopoulos, Ernesto Sanchez and Matteo S. Reorda, "Microprocessor Software-Based Self-Testing", IEEE Design \& Test of Computers, pp. 4-18, May/June, 2010.

[7] Sherif I. Morsy, Mohamed H. El-Mahlawy, Gouda I. Mohamed, "Hybrid based Self-Test Solution for Embedded System on Chip", International Journal of Computer Applications, Volume 84, No 12, December 2013.

[8] M. A. Mousa, "Digital Testing of Analogue Systems,", Ph.D. thesis, Department of Electronic and Electrical Engineering, University of Strathclyde, Glasgow, United Kingdom, October, 2002.

[9] Z. Guo, J. Savir, "Analog Circuit Test using Transfer Function Coefficient Estimates," International Test Conference, pp. 1155 - 1163, 2003.

[10] Milor, L. S. "A tutorial introduction to research on analogue and mixed-signal circuit testing," IEEE Transactions Circuits and Systems-II: Analogue and Digital Signal Processing, vol. 45, pp. 1389-1407, 1998.

[11] Taylor, D., "Transient response testing of analogue components in mixed-signal systems: a review," IEE Proc. Circuits, Devices and Systems, vol. 145, pp. 314-318, 1998.

[12] Towill, D. R.: "The engineering of impulse response testing using pseudo-noise stimuli," Proc. of IEEE Autotestcon, pp. 225-232, 1977.

[13] Robson, M. and Russell, G.: "Digital techniques for testing analogue functions," Proc. of IEE Colloquium 'Systems Design for Testability', Digest No.1995/083, pp. 6/1-4, 1995.

[14] A. Singh, C Patel, J. Plusquellic, "On-Chip Impulse Response Generation for Analog and Mixed-Signal Testing," proceeding of International Test Conference (ITC), 2004

[15] Souders, T. M. and Flach, D. R.: "Accurate frequency response determinations from discrete step response data," IEEE Transaction on Instrumentation and Measurement, vol. IM-36, pp. 433-9, 1987.

[16] Chin, K.R.: "Functional testing of circuits and SMD boards with limited nodal access," Proc. of International Test Conference, pp. 129-43, 1989.

[17] John G. Webster, "Medical Instrumentation Application and Design," Third Edition, Wiley and Sons Inc., 1998.

[18] Pan, C. Y. and Cheng, K. T.: "Pseudorandom testing for mixed-signal circuits," IEEE Transactions Computer-Aided Design of Integrated Circuits and Systems, vol. 18, pp. $1173-1185,1997$

[19] Variyam, P. N., Chatterjee, A.: "Digital-compatible BIST for analog circuits using transient response sampling," IEEE Design \& Test of Computers, pp. 106-115, 2000.

[20] Bekheit, M. A. M., Hamilton, D. J. and Stimpson, B. P.: "Testing analogue circuits with binary sequences: a feasibility study", Proc. of International Mixed-Signal Test Workshop, Montreux-Switzerland, 18-21 June 2002. 
[21] Sunil R. Das, Jila Zakizadeh, Satyendra Biswas, Mansour H. Assaf, Amiya R. Nayak, Emil M. Petriu, WenBen Jone, and Mehmet Sahinoglu, "Testing Analog and Mixed-Signal Circuits With Built-In Hardware - A New Approach," IEEE Transactions on Instrumentation and Measurement, vol. 56, NO. 3, June 2007.

[22] B. K. S. V. L. Varaprasad, Lalit Mohan Patnaik, Hirisave S. Jamadagni, and V. K. Agrawal, "A New ATPG Technique (MultiDetect) for Testing of Analog Macros in Mixed-Signal Circuits," IEEE Transactions on ComputerAided Design of Integrated Circuits and Systems, vol. 23, NO. 2, Feb. 2004.

[23] Jeongjin Roh and Jacob A. Abraham, "Subband Filtering for Time and Frequency Analysis of Mixed-Signal Circuit
Testing," IEEE Transactions on Instrumentation and Measurement, vol. 53, NO. 2, APRIL 2004.

[24] MicroSim Corporation, "MicroSim Application Notes," Version 8.0, June, 1997.

[25] Mohamed. H. El-Mahlawy, "A Novel Testing Method for Monostable Multivibrators," Proceedings of the $5^{\text {th }}$ International Conference of the Electrical Engineering (ICEENG), Military Technical College, Cairo, Egypt, 2006.

[26] R. Kondagunturi, E. Bradley, K. Maggard, C. Stroud, "Benchmark Circuits for Analog and Mixed-Signal Testing," Proceeding of the IEEE Southeast Regional Conference, pp. 217-220, 1999. 